\title{
Palabras inaugurales en Primer Foro Multidisciplinario de Innovación y Emprendimiento
}

\author{
Máximo Andrés Rodríguez Pérez ${ }^{1}$
}

Bienvenidos y bienvenidas a nuestra facultad Regional Multidisciplinaria

Saludos a las personas que presiden este acto:

- Vicerrector General de la Universidad Nacional Autónoma de Nicaragua, Managua, Maestro Jaime López Lowery.

- Sara Amelia Rosales, La Gerente del Banco Central de Nicaragua,

- Miembro del Consejo de Facultad- FAREM-Estelí Maestro Eduardo López Herrera.

Saludos a los invitados especiales todos los expositores, participantes, amigos y de otras universidades y en especial a nuestros colegas de la BICU que nos acompañan como expositores, medios de comunicación, Presidente de la cámara de comercio Reyes Alfonso, delegados de gobierno, representantes de la empresa privada.

Saludos a toda la comunidad universitaria

El día de hoy 19 de Agosto del 2015 estamos celebrando el I FORO MULTIDISCIPLINARIO DE INNOVACION Y EMPRENDIMIENTO en el marco del XIX Congreso Científico de la UNANManagua, Maestro Elmer Cisneros In Memorian, y estamos celebrando este Foro sobre un tema crucial para nuestro país, como es el tema de Innovación y Emprendimiento, por ello el lema de este evento es: Innovar y Emprender aquí y ahora.

En la actualidad, muchos países a nivel mundial han destacado la importancia de fomentar la creatividad, la innovación y el emprendimiento, como aspectos estratégicos para desarrollar una economía más competitiva y a la par dar respuestas a las necesidades de desarrollo social, ambiental y económico.

Una de las mayores preocupaciones está en promover las capacidades de nuestros países para abordar problemáticas concretas, teniendo como denominador común la crisis ambiental, crisis alimentaria, el desempleo, subempleo, y el limitado desarrollo de las micro, pequeñas y medianas empresas.

1 Decano de la Facultad Regional Multidisciplinaria de Estelí y miembro del Consejo Universitario de la UNAN Managua. Correo Eléctronico: max.andrei.rodriguez@gmail.com 
En Nicaragua nuestro Gobierno de Unidad y Reconciliación Nacional (GRUN) se ha comprometido, a través del Plan Nacional de Desarrollo Humano por transformar el modelo de sociedad neoliberal por el Modelo Cristiano, Socialista y Solidario del Poder Ciudadano, el cual se basa en valores cristianos, ideales socialistas y prácticas solidarias que guían la construcción de círculos virtuosos de desarrollo humano con la recuperación de valores, la restitución de derechos y el fortalecimiento de capacidades que han permitido ir superando los círculos vicios de pobreza y subdesarrollo.

La universidad como institución formadora de profesionales del presente y del futuro del país, tiene una enorme responsabilidad frente a los desafíos que este siglo XXI plantea, sobre todo en materia de conocimientos, innovación y emprendimientos. Esta sociedad del conocimiento y de la información, con su acelerado avance obliga a impulsar una praxis educativa innovadora encaminada al emprendimiento que tenga en la investigación la punta de lanza de los aprendizajes significativos de los y las estudiantes, para que el conocimiento, dé respuesta a su formación integral y al desarrollo de la sociedad en los aspectos técnicos, científicos, productivos, ambientales, económicos y culturales.

El compromiso en la formación de profesionales que se correspondan con los nuevos tiempos, solo será posible desde una pedagogía innovadora, en que no se vea a la ciencia como algo acabado, sino en permanente construcción, como un aprendizaje permanente de todos, que pase del yo empírico al sujeto epistémico, que se traduzca en un quehacer innovador y emprendedor, factor de cambio individual y social y desde luego que también nacional, porque la Universidad está en función de los grandes retos de la nación, en este sentido la UNAN-Managua se ha comprometido al impulso del Plan Nacional de Desarrollo 2012-2016, que en materia de innovación y emprendimiento señala lo siguiente: "En Nicaragua, la Ciencia, la Tecnología, la Innovación y el Emprendimiento serán motores centrales para la transformación económica y social en el mediano y largo plazo. Las innovaciones tecnológicas producto del desarrollo del conocimiento, generan mayor competitividad de las empresas y los países, agregando valor a sus productos y servicios". Lo anteriormente señalado está en correspondencia con el plan estratégico de la universidad 20112015, que señala: "La universidad tiene grandes retos: debe prevalecer su calidad sin menoscabar su crecimiento; debe mantenerse en la cúspide de sus planteamientos innovadores y de sus propuestas metodológicas, organizativas y curriculares; debe proyectarse como la universidad del futuro, la de mayor actualidad, la universidad cuya reserva moral impregne de profesionalismo a sus académicos y graduados y debe seguir siendo la Universidad Pública ejemplar, cuya rendición social de cuentas refleja el estado positivo de su avance".

Así mismo, los procesos de innovación y emprendimiento deberán estar en sintonía con el modelo educativo de la universidad, que dice lo siguiente: "El modelo está centrado en las personas, que contribuye con el desarrollo integral de los estudiantes. Un modelo que articula las acciones de los diferentes actores partícipes en el quehacer educativo de la universidad, y que además, orienta la formación de profesionales con una concepción científica y humanista, capaces de interpretar los fenómenos sociales y naturales con un sentido crítico, reflexivo y propositivo". 
Sobre la base del nuevo modelo de gestión universitaria de la UNAN-Managua, se promueve e implementa el Modelo I+D+ì, que tiene tres grandes procesos principales: 1) La investigación; 2) La innovación; y 3) El desarrollo tecnológico.

En la FAREM Estelí, se han estado dando pasos significativos en materia de innovación y emprendimientos, como se demuestra en novedosos productos que han realizado los estudiantes en el contexto de la relación con la Universidad Estatal Grand Valley de Michigan, la Jornada Universitaria de Desarrollo Científico (JUDC), las ferias de mercadotecnia, las Ferias Territoriales promovidas por el CNU, Hemos participado en los Concursos de innovación promovido por CONYCIT, entre otras actividades. En el 2014 ganamos el primer lugar a nivel nacional en el rally latinoamericano de innovación, donde participaron diferentes universidades de Nicaragua y Latinoamérica. Participaron varios estudiantes y su tutor el profesor Juan Carlos Vargas. En este 2015 ganamos el primer lugar en el curso de innovación de mayo 2015. Con el producto compactadora para basura. Elaborado por varios profesores de nuestra facultad, liderados por el profesor Luis Fuentes. Y recientemente nuestra facultad, ha sido premiada por la Universidad Carlos III de Madrid con el primer premio internacional de tecnología apropiada 2015, que lo ganó nuestra alumna Thelma Karelia Mayorga, con el proyecto cargador solar para dispositivos de bajo voltaje en comunidades rurales de Nicaragua. Sus tutores fueron los profesores Rubén Dormus, Emilio Lanuza Y mención especial para cocinas tipo Jarened para comunidades rurales que lo elaboró Jarelia Maldonado y su tutor el profesor Edwin Reyes.

Todas estos esfuerzos han tenido como complemento la relación universidad-empresa - estado, que estructura todo un universo que debe apuntar al desarrollo y consolidación de un círculo virtuoso en la medida en que toda la comunidad universitaria asuma los retos de mediano y largo plazo que representan el innovar y el emprender, para lo cual será de capital importancia la inversión que se realice en infraestructura, equipos y herramientas y de esa manera responder a las necesidades más sentidas de la sociedad y del país.

En esta universidad, los aprendizajes deben partir de la curiosidad, de la observación, del ensayo y el error, de lo que no está resuelto, de la competencia cognitiva y esto es aprender desde la innovación, de la investigación, es decir, una forma de hacer pedagogía que rompa con viejos esquemas que desde la universidad ya no deben ser viables, visto desde la perspectiva de una universidad que sea pertinente con las transformaciones que demanda el cambio de época que se vive, signada además por una economía del conocimiento que demanda mayor innovación y por lo tanto capacidad tecnológica para producir competitivamente y de manera sostenida bienes y servicios.

Una educación universitaria que tenga su base en la investigación y que los aprendizajes se sustenten en ella, deberá forjar profesionales que al volcar sus conocimientos a la economía del país, a la producción o a cualquier campo ligado al desarrollo nacional, tiene que incidir en la productividad, 
en los niveles de producción que han sido un talón de Aquiles que ha frenado el desarrollo, por lo que el complemento de estos aprendizajes, además del acervo de conocimientos tecnológicos, es una cultura empresarial que conlleve a la creación de negocios, que generen productos de calidad y competitivos que reflejen una cultura emprendedora.

Hoy inauguramos el I Foro Multidisciplinario de Innovación y Emprendimiento con el lema Innovamos y Emprendemos aquí y ahora, porque estas acciones ya no pueden seguir esperando, nosotros hoy estamos demostrando que nuestra universidad está trabajando con compromiso social por el desarrollo de nuestro país. El día de hoy ustedes podrán ser partícipes de estos avances en las 34 ponencias de las 10 mesas temáticas que se organizaron para este evento científico. Y en la Feria de Tecnología e Innovación estamos presentando más de 30 prototipos, proyectos u obras demostrativas.

En definitiva, la cultura investigativa debe marcar el presente y el futuro de la universidad y con ella sentar las bases innovadoras y emprendedoras, como elementos claves de este nuevo siglo y que la universidad debe potenciar como respuesta pedagógica, técnica, científica, productiva y económica.

¡iMuchas gracias!! 